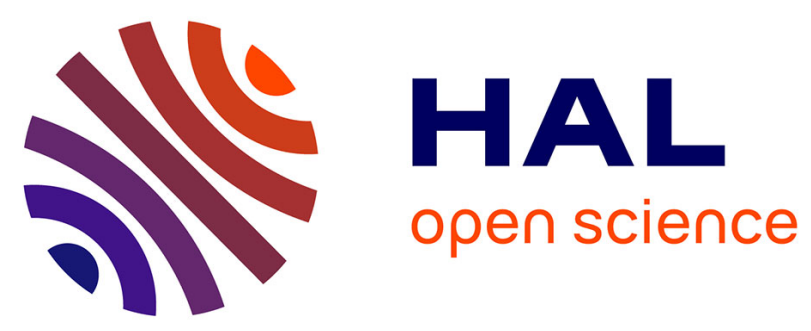

\title{
Influence of Titanium on the High Temperature Oxidation and Chromia Volatilization of Ternary $\mathrm{Ni}-\mathrm{Cr}-\mathrm{C}$ Alloys
}

Patrice Berthod, Floriane Allègre, Estelle Kretz

\section{- To cite this version:}

Patrice Berthod, Floriane Allègre, Estelle Kretz. Influence of Titanium on the High Temperature Oxidation and Chromia Volatilization of Ternary Ni-Cr-C Alloys. Oxidation of Metals, 2016, 86 (5-6), pp.581-595. 10.1007/s11085-016-9656-6 . hal-02181313

\section{HAL Id: hal-02181313 \\ https://hal.science/hal-02181313}

Submitted on 12 Jul 2019

HAL is a multi-disciplinary open access archive for the deposit and dissemination of scientific research documents, whether they are published or not. The documents may come from teaching and research institutions in France or abroad, or from public or private research centers.
L'archive ouverte pluridisciplinaire HAL, est destinée au dépôt et à la diffusion de documents scientifiques de niveau recherche, publiés ou non, émanant des établissements d'enseignement et de recherche français ou étrangers, des laboratoires publics ou privés. 


\title{
Influence of Titanium on the High Temperature Oxidation and Chromia Volatilization of Ternary Ni-Cr-C Alloys
}

\author{
Patrice Berthod, Floriane Allègre, Estelle Kretz \\ Institut Jean Lamour (UMR CNRS 7198), Department CP2S, Faculty of Science and Technologies, Postal Box \\ 70239, 54506 Vandoeuvre-lès-Nancy, FRANCE
}

\author{
patrice.berthod@centraliens-lille.org, floriane.allegre6@etu.univ-lorraine.fr, estelle.kretz@hotmail.fr
}

\begin{abstract}
Two ternary alloys, $\mathrm{Ni}-25 \mathrm{Cr}-0.25 \mathrm{C}$ and $\mathrm{Ni}-25 \mathrm{Cr}-0.50 \mathrm{C}$ (wt.\%) and three versions containing also titanium ( 1 and $2 \mathrm{wt} . \%$ ) were cast and submitted to oxidation in dry synthetic air at $1200^{\circ} \mathrm{C}$ to observe the effects of titanium on the behaviors of the nickel-based alloys belonging to this category. The mass gains are wholly parabolic in all cases and the values of the parabolic and chromia-volatilization constants are typical of a chromia-forming behavior. The mass gains of the Ti-containing alloys are faster than for the $\mathrm{Ni}-\mathrm{Cr}-\mathrm{C}$ alloys, and these kinetic differences are consistent with the differences in chromia thickness and in Cr-impoverishment of the subsurface. In addition the presence of $\mathrm{Ti}$ led to the development of thin a $\mathrm{TiO}_{2}$ outer scale isolating chromia from hot air, but without benefit for the protection of $\mathrm{Cr}_{2} \mathrm{O}_{3}$ against volatilization. The obtained results also suggest that Ti may perturb the $\mathrm{Cr}$ diffusion in volume but also delay the oxide spallation during cooling.
\end{abstract}

Keywords: Nickel-based alloys; Titanium; Chromium carbides; High temperature oxidation; Mass gain rates; Oxide scale characteristics; Internal oxidation

Post-print version of the article Oxid Met (2016) 86:581-595; DOI 10.1007/s11085-016-9656-6

\section{INTRODUCTION}

Nickel-based alloys represent a particularly important class of superalloys for high temperature applications [1]. The most remarkable ones are the $\gamma / \gamma^{\prime}$ single crystals which offer very high levels of high temperature mechanical properties [2-4] and oxidation resistance [5-8]. Essentially devoted to constitute elongated pieces, these singlecrystal alloys are unfortunately not suitable to the compact geometries of many complex-shaped components for which other elaboration/shaping techniques must be preferred (conventional foundry, powder metallurgy...). However there are also polycrystalline nickel-based superalloys which can be employed for pieces with compact or complex shapes. In the case of these latter Ni-based alloys oxidation resistance at elevated temperature can be achieved with high amounts in chromium in their chemical compositions, instead aluminum is less efficient than $\mathrm{Cr}$ against corrosion by molten substances (CMAS, glasses...). Unfortunately, the protective external scale of chromia formed all around the Cr-rich superalloys tends to be re-oxidized into volatile species. This volatilization phenomenon is harmful for the sustainability of the oxidation resistance [9], especially when the working temperature is significantly higher than $1000^{\circ} \mathrm{C}$.

Solutions for limiting chromia volatilization may be very interesting for keeping the longest time possible the chromia-forming behavior of superalloys. Adding reactive elements can be envisaged in this field, by hoping developing, together with chromia, another type of oxide whose presence may stabilize or protect $\mathrm{Cr}_{2} \mathrm{O}_{3}$ from volatilization. Titanium, which is widely used for light alloys with high specific mechanical properties and oxidation resistance at moderate temperatures [10-14], is one of such elements reacting easily with oxygen. Since this element seems to have never been evocated in association with the chromia volatilization phenomenon in the literature, it can be interesting to undertake a work to study whether Ti can have a positive effect in nickel-based chromia-forming superalloys by limiting the volatilization of $\mathrm{Cr}_{2} \mathrm{O}_{3}$ at elevated temperature. This was done here at $1200^{\circ} \mathrm{C}$, temperature high enough to promote significant volatilization of chromia, easy to characterize by thermogravimetry and to evidence a possible effect of titanium on this phenomenon. 


\section{EXPERIMENTAL}

A series of five cast nickel-based alloys, containing first chromium in rather high quantity to favor a chromiaforming behavior and second interdendritic chromium carbides themselves favorable to an easy supplying of the oxidation front in $\mathrm{Cr}$, were chosen to be sure to really obtain a chromia-forming behavior. Indeed it is known that $\mathrm{Cr}$ diffuses easily in the austenitic nickel matrix, much easier than in cobalt-based alloys for example. Chromium diffusion is furthermore helped by the presence of chromium carbides in the interdendritic spaces. High enough but still moderate levels of titanium were considered, in order to favor the observation of the possible effect of this element but without risking disturbing the microstructures of the model alloys. Three Ti-containing alloys were thus prepared by casting: $\mathrm{Ni}-25 \mathrm{Cr}-0.25 \mathrm{C}-1 \mathrm{Ti}$ ("NiTi1" alloy), $\mathrm{Ni}-25 \mathrm{Cr}-0.50 \mathrm{C}-1 \mathrm{Ti}$ ("NiTi2-1" alloy) and Ni-25Cr-0.50C2Ti ("NiTi2-2" alloy). There were produced by melting in inert atmosphere (300 mbars of pure Ar) by using a CELES high frequency induction furnace. The melting of each mix of pure elements (Ni, Cr, Ti: from Alfa Aesar, purtity $>99.9 \%$, and C: graphite, purity $>99.99 \%$ ) was achieved in the water-cooled copper crucible of the furnace. After heating leading to total fusion, the liquid alloy was isothermally maintained during five minutes. Solidification and cooling down to ambient temperature were carried out in the copper crucible. For evidencing the possible effects of the presence of titanium two reference nickel-based Ti-free alloys with the same amounts in $\mathrm{Cr}$ and $\mathrm{C}$ were synthesized in parallel (Ni-25Cr-0.25C, "Ni1" alloy, and $\mathrm{Ni}-25 \mathrm{Cr}-0.50 \mathrm{C}$, "Ni2" alloy), following the same elaboration procedure.

Five compact $40 \mathrm{~g}$-weighing ingots were thus obtained. They were cut for obtaining samples of two types: metallographic samples for the examination of the as-cast microstructures, and parallelepiped samples for the oxidation tests (approximate dimensions: $8 \mathrm{~mm} \times 8 \mathrm{~mm} \times 3 \mathrm{~mm}^{3}$ ). The samples for metallography examinations were embedded in a cold resin mixture (resin CY230 + hardener HY956, ESCIL), and ground using SiC-enriched papers with grade varying from 120 to 1200 . After cleaning using ultrasonic vibrations in water, they were polished using textile containing $1 \mu \mathrm{m}$-alumina particles, to obtain a mirror-like state for all metallographic samples to allow their examination using electron microscopy.

The parallelepiped samples destined to the thermogravimetric tests were polished with SiC-papers (120 to 1200 grit). Edges and corners were smoothed using 1200-grit paper. A SETARAM TGA92 thermo-balance was used for the oxidation runs for recording the mass variations versus time, in a $1.5 \mathrm{~L} /$ hour flow of dry synthetic air $\left(80 \% \mathrm{~N}_{2}-\right.$ $20 \% \mathrm{O}_{2}$ ). The applied thermal cycle was composed of a heating at $+20^{\circ} \mathrm{C} / \mathrm{min}$, an isothermal stage of $46 \mathrm{~h}$ at $1200^{\circ} \mathrm{C}$ and of a cooling rate at $-5^{\circ} \mathrm{C} / \mathrm{min}$ to favor the keeping of the external oxide scales. The mass gain files were first plotted versus time to preliminarily see whether the kinetic is parabolic or not. The mass gain per surface unit area (m) was thereafter plotted versus the square root of time to determine the parabolic constant $\mathrm{k}_{\mathrm{p}}$ by applying an usual method. After having verified by X-ray diffraction that the external oxide scales were mainly chromia, its volatilization rate was assessed, as well as a more accurate $\mathrm{kp}$ constant (not minimized by the volatilization of chromia), by analyzing the mass gain files according to the $\left\{\mathrm{m} \times \mathrm{dm} / \mathrm{dt}=\mathrm{k}_{\mathrm{p}}-\mathrm{k}_{\mathrm{v}} \times \mathrm{m}\right\}$ method [15], where $\mathrm{m}$ is the mass gain per surface unit area.

After the oxidation runs, the oxidized samples underwent metallographic characterization. This was done first by photographing the oxidized surfaces and measuring the fraction of surface where the external oxide scale obviously quitted the alloy, in order to characterize the amplitude of the oxide spallation when it occurred during cooling. Second, X-Ray Diffraction (XRD) runs were performed on the external oxide scales using a Philips X'Pert Pro diffractometer, for identifying the natures of the external oxides still present on surface.

A thin gold layer was thereafter deposited all around the oxidized samples by cathodic pulverization, followed by the electrolytic deposition of a nickel shell devoted to the protection of the external oxide during cutting. Cutting in two parts, embedding in cold resin mixture and grinding/polishing to obtain a mirror-like surface led to crosssectional samples ready to be examined by microscopy. Observations were done using electron microscopy (Scanning Electron Microscope JEOL JSM 6010LA), and Energy Dispersion Spectrometry (EDS apparatus attached to the SEM).

\section{RESULTS}

\section{Chemical Compositions and Microstructure of the Studied Alloys}

The chemical compositions of all the five alloys are given in Table 1. The wished contents in $\mathrm{Cr}$ and $\mathrm{Ti}$ were successfully reached, despite the high reactivity of $\mathrm{Cr}$ and especially Ti. However a few titanium oxides, nitrides and 
carbo-nitrides, identified by EDS spot analysis are present in the Ti-containing alloys, as illustrated in Figure 1 by SEM/BSE micrographs. In these ones one can see that the microstructures of the titanium-containing alloys are composed of an austenitic dendritic matrix of nickel-based solid solution (containing about 23 wt. $\% \mathrm{Cr}$ for the $0.25 \mathrm{C}$-containing alloy, and around $21.5 \mathrm{wt} . \% \mathrm{Cr}$ for the two $0.50 \mathrm{C}$-containing alloys) in which almost all the titanium atoms are present in solid solution, and of interdendritic chromium carbides which were identified by spot EDS analysis as being $\mathrm{Cr}_{7} \mathrm{C}_{3}$.

\section{Mass gain kinetics}

The obtained mass gain curves are plotted in Figure 2 for the two 0.25 wt.\%C-containing alloys (Ni1 and NiTi1) and in Figure 3 for the three 0.50wt.\%C-containing ones (Ni2, NiTi2-1 and NiTi2-2 alloys). All the mass gain curves are globally parabolic and the determination of the classical $k_{p}$ values did not pose any problem. Since the external oxide scales were essentially composed of chromia, as this will be evidenced further, the mass gain files were also plot as $\mathrm{m} \times \mathrm{dm} / \mathrm{dt}$ versus $-\mathrm{m}$ in order to determine the values of the two constants describing the oxidation kinetic. This was remarkably successful since the $\{\mathrm{m} \times \mathrm{dm} / \mathrm{dt}$ versus $-\mathrm{m}\}$ plots led to linear parts (top of Figure 4 for the NiTi1 alloy, Figure 5 for NiTi2-1 and Figure 6 for NiTi2-2), the equations of which allowed determining the values of the volatilization constant (slope of the regression straight line) and the real parabolic constant (ordinate at the origin). The linear $\mathrm{k}_{\mathrm{v}}$ constant characterizing the rate of volatilization of chromia, and the real parabolic $\mathrm{k}_{\mathrm{p}}$ constant (not underestimated since the mass loss in chromium by leaving $\mathrm{CrO}_{3}$ is then taken into account) were then determined (Table 2). As illustrated by the graphs presented in the bottom parts of the Figures 4 , 5 and 6 , these values were validated by the very good correspondence between the theoretic mass gain curves calculated from these values of $\mathrm{k}_{\mathrm{p}}$ and $\mathrm{k}_{\mathrm{v}}$ (green curves) and the experimental mass gain curves (black curves). The theoretic curves plotted with the conventionally determined $\mathrm{k}_{\mathrm{p}}$ (red curves) do not match so exactly. Additionally, the linear constant $\mathrm{k}_{1}$ associated to the transient oxidation at the beginning of the isothermal stage was also determined (on the classical $\mathrm{m}=\mathrm{f}(\mathrm{t})$ plot).

The three Ti-containing alloys oxidized faster than the two Ti-free alloys. This is graphically visible and confirmed by the values of the parabolic constants. Furthermore, the volatilization constants determined for the Ticontaining alloys seem to be globally higher than for the Ti-free alloys (average $\mathrm{k}_{\mathrm{v}}$ of $95 \times 10^{-10} \mathrm{~g} \mathrm{~cm}^{-2} \mathrm{~s}^{-1}$ for the Ti-containing alloys against $81 \times 10^{-10} \mathrm{~g} \mathrm{~cm}^{-2} \mathrm{~s}^{-1}$ for the Ti-free ones).

\section{Oxide spallation during cooling}

After return at room temperature, it is obvious that some of the oxidized Ti-containing samples have lost only small parts of their external oxide scales, by comparison with the two ternary Ti-free alloys (Figure 7). Since the Ticontaining alloys did not lose anywhere their external oxide scale on the whole thickness the metal surface was visible and image analysis led to $0 \%$ of surface having lost the external oxide scale, even if it is obvious if some small parts of oxide were lost. This is different for the Ti-free alloys for which areas having lost their external oxide were clearly visible: they represent (average values for both main faces) $29 \%$ and $17 \%$ for the Ni1 and Ni2 alloys respectively.

The start of spallation during the cooling phase can be easily observed on the \{mass versus temperature $\}$-curves. Figure 8 (the two Ti-containing and Ti-free 0.25C-containing alloys) and Figure 9 (the two Ti-containing and Ti-free $0.50 \mathrm{C}$-containing alloys) show that spallation started at $688^{\circ} \mathrm{C}$ for the NiTi1 alloy (i.e. a little later than the Ni1 one: $832^{\circ} \mathrm{C}$ ), at $702^{\circ} \mathrm{C}$ and $737^{\circ} \mathrm{C}$ for the NiTi2-1 and NiTi2-2 alloys respectively (later than the Ni2 alloy: $817^{\circ} \mathrm{C}$ ). In addition the mass variations along the whole thermal cycle were much more limited by comparison with the two ternary alloys (for which the total mass variation is negative!).

\section{Analysis of the external oxides and of the subsurfaces}

X-ray diffraction was carried out on the oxidized surfaces of the five alloys (example of NiTi1 in Figure 10). Unsurprisingly, chromia is present over all the oxidized surfaces but there is also a significant presence of $\mathrm{TiO}_{2}$. The two oxides are shown in the cross-sectional SEM/BSE micrographs given in Figure 11 for NiTi1, and in Figure 12 for NiTi2-1 and NiTi2-2, and the results of the measurements of the oxide scale thickness or carbide-free zone depth 
are given in Table 3 (average and standard deviation of five values). It appears that all alloys are covered by a continuous chromia layer (identified by EDS) which seems thicker for the Ti-containing alloys than for the Ti-free ones. Indeed the chromia scales formed over the Ni1 and Ni2 alloys (around $22 \mu \mathrm{m}$ ) are 10 $\mu \mathrm{m}$ lower than the ones

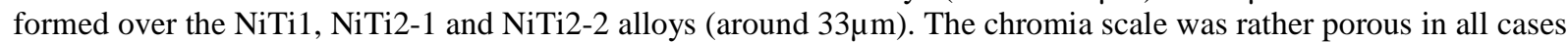
but maybe more for the Ti-containing alloys than for the Ti-free ones. In addition, for the Ti-containing alloys, a seemingly continuous outer layer made of $\mathrm{TiO}_{2}$ exists and its thickness tends to increase with the Ti content in alloy (around $3 \mu \mathrm{m}$ for NiTi1 and NiTi2-1 against $5 \mu \mathrm{m}$ for NiTi2-2). This outer $\mathrm{TiO}_{2}$ oxide scale seems having been lost in some locations. This can be due to metallographic preparation but it is also possible that parts of $\mathrm{TiO}_{2}$ were also lost during the cooling, spallation detected on the cooling part of the $\{\mathrm{m}$ versus temperature $\}$-plotted thermogravimetry curves Figure 8 and Figure 9) and visible on the oxidized surfaces of the samples (Figure 7). Under the external scales carbides seemingly disappeared from the oxidation front, over a depth which is lower for the $0.50 \mathrm{C}$-containing alloys than for the $0.25 \mathrm{C}$-containing ones. These carbide-free zones tend to be a little deeper for the Ti-free alloys than for the Ti-containing alloys for a given carbon content. As expected they are impoverished in $\mathrm{Cr}$ and $\mathrm{Ti}$ (the ternary alloys only in $\mathrm{Cr}$ ), as illustrated by the concentration profiles given in Figure $13(0.25 \mathrm{C}$ containing alloys) and Figure 14 (0.50C-containing alloys). The titanium contents in the matrix are equal to 0 in the extreme surface and they increase progressively when one goes deeper, this evidencing the diffusion of Ti towards the oxidation front. The same classical observation can be done for chromium. Globally the Cr-depleted depths correspond to the carbide-free zones while the titanium-depleted depths are more extended inwards. One can notice that the $\mathrm{Cr}$ content in extreme surface tends to be lower for the Ti-containing alloys than for the Ti-free ones, demonstrating that the former ones seem being threatened by the loss of the chromia-forming behavior than the latter ones.

\section{DISCUSSION}

Despite its high reactivity with oxygen and nitrogen titanium was thus successfully introduced in these base ternary alloys during conventional casting. It is true that even pure argon may contain extremely low quantities of $\mathrm{O}$ or $\mathrm{N}$ but high enough to allow Ti reacting with them. A few titanium oxides, nitrides or carbo-nitrides were present but they did not perturb the study. Titanium was almost exclusively present in solid solution without forming carbides, showing that $\mathrm{TiC}$ are less stable than chromium carbides in these nickel-based $25 \mathrm{wt} \% \mathrm{Cr}$-containing alloys.

The isothermal oxidation kinetics of the three Ti-containing alloys were of a parabolic type without any jumps, as the corresponding Ti-free ternary alloys. By comparison by these latter ones the mass gains of the Ti-containing alloys were significantly faster. This can be due to the participation of $\mathrm{Ti}$ in the formation of oxides $\left(\mathrm{TiO}_{2}\right.$ both internal and external), but it is also true that the external chromia scales were thicker than for the ternary alloys. Furthermore chromia seemed more porous than the ones formed over the ternary alloys. The reasons of these two differences are not evident and needs to be deepened.

$\mathrm{TiO}_{2}$ oxides formed internally and also externally. This second part of oxides is located outside and constitutes a thin layer which seems isolating chromia from hot air. Unfortunately this $\mathrm{TiO}_{2}$ external layer covering the chromia scales obviously did not protect it from contact with the oxidizing atmosphere since the chromia volatilization constants of the Ti-containing alloys tend to be not lower but higher than for the Ti-free alloys. It is true that the outer $\mathrm{TiO}_{2}$ scale obviously contains defects (pores...) which do not allow it totally isolating chromia from outside. The chromia scales observed on the Ti-containing surfaces are thicker than the ones formed over the Ti-free alloys, not because lower volatilization rates but because faster oxidation. This is confirmed by the consumption of chromium coming from the alloys which is greater for the Ti-containing alloys than for the Ti-free ones, as proven by the $\mathrm{Cr}$ profiles presented in Figure 13 and Figure 14. Furthermore, the average $\mathrm{Cr}$ gradients in subsurface are higher for the Ti-containing alloys than for the Ti-free ones, this suggesting that, even if the final mass gain rates were higher in the first case than in the second case, $\mathrm{Cr}$ diffused easier in absence of $\mathrm{Ti}$ in the matrix. Such an obstruction effect of the $\mathrm{Cr}$ diffusion due to Ti may threaten the chromia-forming behavior.

Thus, the presence of 1 or $2 \mathrm{wt} . \% \mathrm{Ti}$ in the model ternary alloys was rather detrimental for the high temperature oxidation behavior of the alloys, but benefit was observed concerning the maintenance of the external scales over the samples during the cooling: spallation started later (i.e. at a lower temperature) during the post-isothermal stage cooling and the final mass loss was much lower than for the Ti-free alloys. It is not really possible to say presently if this due to the $\mathrm{TiO}_{2}$ outer oxide scale or to a possible pegging effect (e. g. very small particles involving Ti favoring 
the adherence of chromia on the alloy). This positive influence of Ti can be of great importance in case of thermal cycling.

\section{CONCLUSION}

The presence of titanium in chromium-rich nickel-based alloys is not neutral for the oxidation behavior at high temperature. Here studied in the case of alloys based on ternary alloys of the $\{\mathrm{Ni}-25 \mathrm{Cr}-0.25$ or 0.50$\}$-type, known to be chromia-forming and well resistant against oxidation in air even at very high temperatures, one clearly saw differences in terms of mass gain rates, oxide thickness, subsurface Cr-depletion, resistance against spallation and even of carbide-free depths. Globally Ti behaved here as rather detrimental in isothermal conditions and, in contrast, as rather beneficial in varying temperature conditions. In contrast, with what was observed for the Ti-free alloys (e.g. slower mass gain for $0.5 \mathrm{wt} . \% \mathrm{C}$ than for $0.25 \mathrm{wt} . \% \mathrm{C}$ ) it was also pointed out that the oxidation behavior of the Ti-containing alloys did not globally depend on the carbon content (except of course the carbide-free depth, as usually observed for carbides-containing cast alloys).

The reasons of these effects of titanium, to confirm for other temperatures and durations of oxidation and other cooling rates, will be deeper studied in future investigations.

\section{ACKNOWLEDGMENTS}

The authors wish to thank Mélissa Ritouet and Thierry Schweitzer for their technical help.

\section{REFERENCES}

1. M. J. Donachie, S. J. Donachie, Superalloys: A Technical Guide (2 ${ }^{\text {nd }}$ Edition), Materials Park: ASM International, 2002.

2. K. L. Gasko, G. M. Janowski, B. J. Pletka, Materials Science \& Engineering A: Structural Materials: Properties, Microstructure and Processing, A104, 1 (1988).

3. N. El-Bagoury, Q. Mohsen, Phase Transitions, 84, 1108 (2011).

4. M. J. Wong, P. G. Sanders, J. P. Shingledecker, C. L. White, Metallurgical and Materials Transactions A: Physical Metallurgy and Materials Science, 46, 2947 (2015).

5. F. H. Latief, K. Kakehi, Y. Tashiro, Journal of Industrial and Engineering Chemistry, 19, 1926 (2013).

6. G. Brewster, I. M. Edmonds, S. Gray, Oxidation of Metals, 81, 345 (2014).

7. Q. Ding, ,Z. Shen, S. Xiang, H. Tian, J. Li, Z. Zhang, Journal of Alloys and Compounds, 651, 255 (2015).

8. C. K. Sudbrack, D. L. Beckett, R. A MacKay, JOM, 67, 2589 (2015).

9. D. Young, High Temperature Oxidation and Corrosion of Metals, Amsterdam: Elsevier Corrosion Series, 2008.

10. P. Pototzky, H. J. Maier, H. J. Christ, Metallurgical and Materials Transactions A: Physical Metallurgy and Materials Science, 29A, 2995 (1998).

11. M. Es-Souni, Materials Characterization, 46, 365 (2001).

12. G. Biallas, M. Essert, H. J. Maier, International Journal of Fatigue, 27, 1485 (2005).

13. T. Wang, H. Guo, Y. Wang, X. Peng, Y. Zhao, Z. Yao, Materials Science \& Engineering A: Structural Materials: Properties, Microstructure and Processing, A528, 2370 (2011).

14. T. Wang, H. Guo, Z. Yao, Z. Zhao, S. Fu, Y. Zhang, Materials Science Forum, 747-748, 860 (2013).

15. P. Berthod, Oxidation of Metals 64(3/4), 235 (2005). 
TABLE 1. Chemical compositions of the five nickel-based alloys (SEM/EDS measurements; +/- 1wt.\%)

\begin{tabular}{cclc}
\hline Elements & $\boldsymbol{C r}$ & \multicolumn{1}{c}{} & $\boldsymbol{T}$ \\
\hline Ni1 & $25.1 \pm 0.2$ & nominally 0.25 & $/$ \\
\hline NiTi1 & $25.4 \pm 0.1$ & nominally 0.25 & $1.0 \pm 0.1$ \\
\hline Ni2 & $25.2 \pm 0.2$ & nominally 0.50 & $/$ \\
\hline NiTi2-1 & $25.7 \pm 0.1$ & nominally 0.50 & $1.1 \pm 0.1$ \\
\hline NiTi2-2 & $25.5 \pm 0.3$ & nominally 0.50 & $2.1 \pm 0.1$ \\
\hline
\end{tabular}

TABLE 2. Values of the linear constant $k_{1}$, of the parabolic constant $k_{p}$ and of the constant chromia volatilization constant $\mathrm{k}_{\mathrm{v}}$, the two later ones being derived from the $\mathrm{m} \times \mathrm{dm} / \mathrm{dt}=\mathrm{f}(\mathrm{m})$ plots.

\begin{tabular}{|c|c|c|c|c|}
\hline Constants & $k_{l}\left(\times 10^{-8} \mathrm{~g} / \mathrm{cm}^{2} / \mathrm{s}\right)$ & \multicolumn{2}{|c|}{$k_{p}\left(\times 10^{-12} g^{2} \mathrm{~cm}^{-4} \mathrm{~s}^{-1}\right)$} & $k_{v}\left(\times 10^{-10} \mathrm{~g} / \mathrm{cm}^{2} / \mathrm{s}\right)$ \\
\hline method & slope at stage start & classic & $\mathrm{m} \times \mathrm{dm} / \mathrm{dt}=\mathrm{f}(-\mathrm{m})$ & $\mathrm{m} \times \mathrm{dm} / \mathrm{dt}=\mathrm{f}(-\mathrm{m})$ \\
\hline Nil & 89 & 24 & 40 & 68 \\
\hline NiTi1 & 34 & 51 & 86 & 110 \\
\hline $\mathrm{Ni} 2$ & 25 & 15 & 32 & 93 \\
\hline NiTi2-1 & 21 & 54 & 76 & 73 \\
\hline NiTi2-2 & 24 & 51 & 85 & 101 \\
\hline
\end{tabular}

TABLE 3. Values of the linear constant $\mathrm{k}_{\mathrm{l}}$, of the parabolic constant $\mathrm{k}_{\mathrm{p}}$ and of the constant chromia volatilization constant $\mathrm{k}_{\mathrm{v}}$, the two later ones being derived from the $\mathrm{m} \times \mathrm{dm} / \mathrm{dt}=\mathrm{f}(\mathrm{m})$ plots.

\begin{tabular}{cccc}
\hline $\begin{array}{c}\text { Thicknesses or } \\
\text { depths }(\boldsymbol{\mu m})\end{array}$ & $\mathbf{T i O}_{\mathbf{2}}$ & $\boldsymbol{C r}_{\mathbf{2}} \boldsymbol{O}_{\mathbf{3}}$ & Carbide-free zone \\
\hline Ni1 & $/$ & $19.6 \pm 2.1$ & $181 \pm 11$ \\
\hline NiTi1 & $3.5 \pm 0.3$ & $32.8 \pm 0.5$ & $156 \pm 8$ \\
\hline Ni2 & $/$ & $23.7 \pm 2.4$ & $124 \pm 9$ \\
\hline NiTi2-1 & $2.3 \pm 0.3$ & $32.9 \pm 1.8$ & $123 \pm 6$ \\
\hline NiTi2-2 & $4.6 \pm 0.7$ & $33.1 \pm 1.4$ & $114 \pm 3$ \\
\hline
\end{tabular}




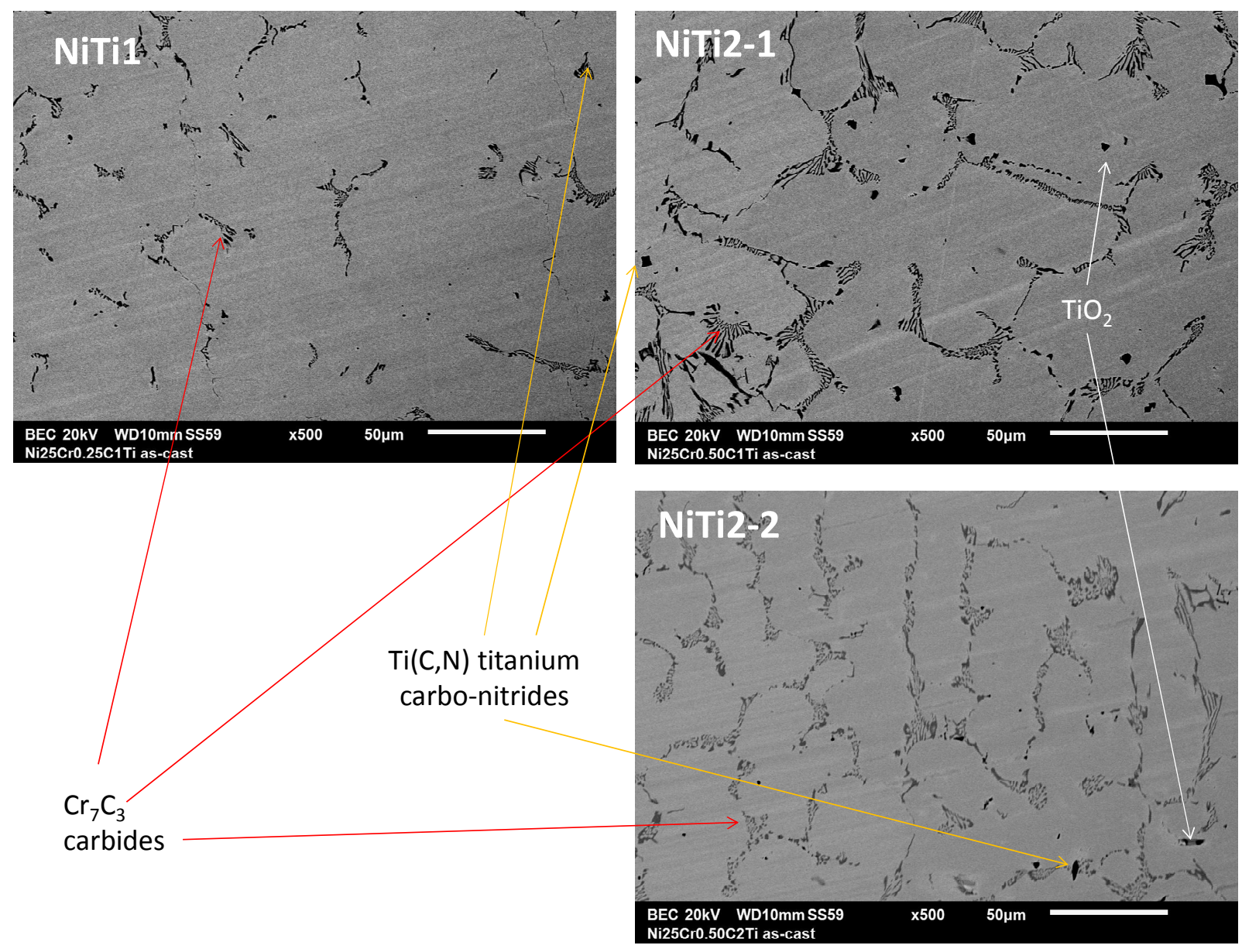

FIGURE 1. SEM/BSE micrographs of the as-cast microstructures of the three Ti-containing Ni-based alloys 


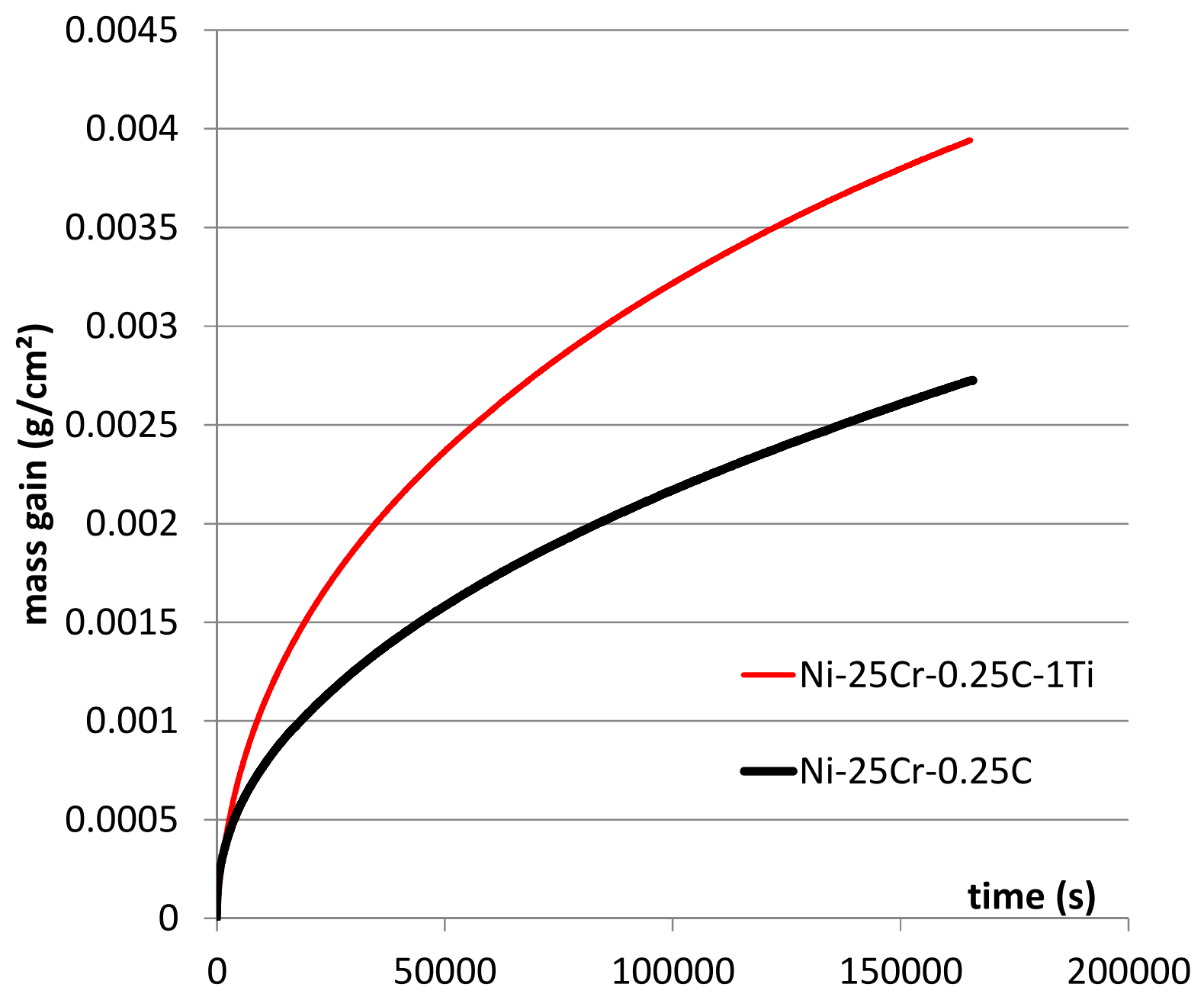

FIGURE 2. The mass gain curves obtained for the two $0.25 \mathrm{C}$-containing alloys 


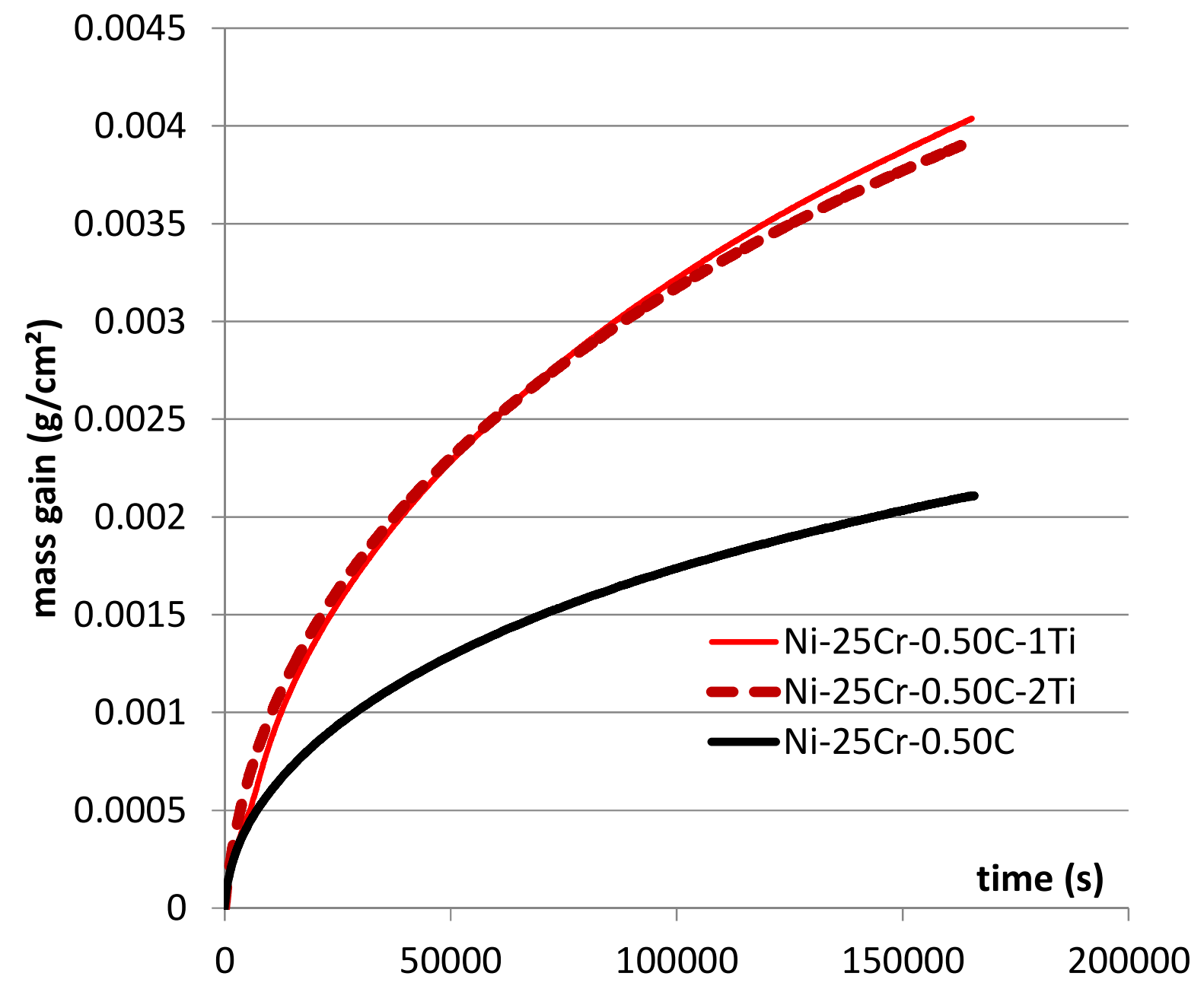

FIGURE 3. The mass gain curves obtained for the three $0.50 \mathrm{C}$-containing alloys 


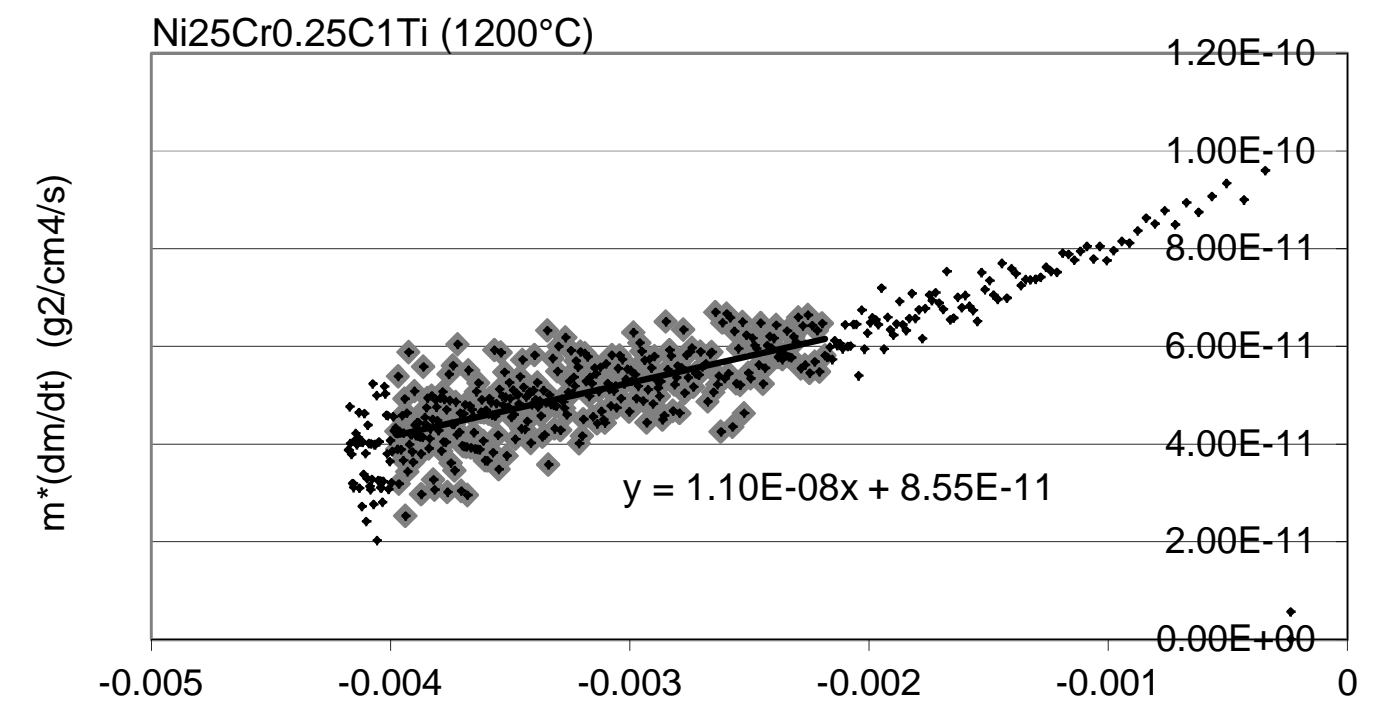

A

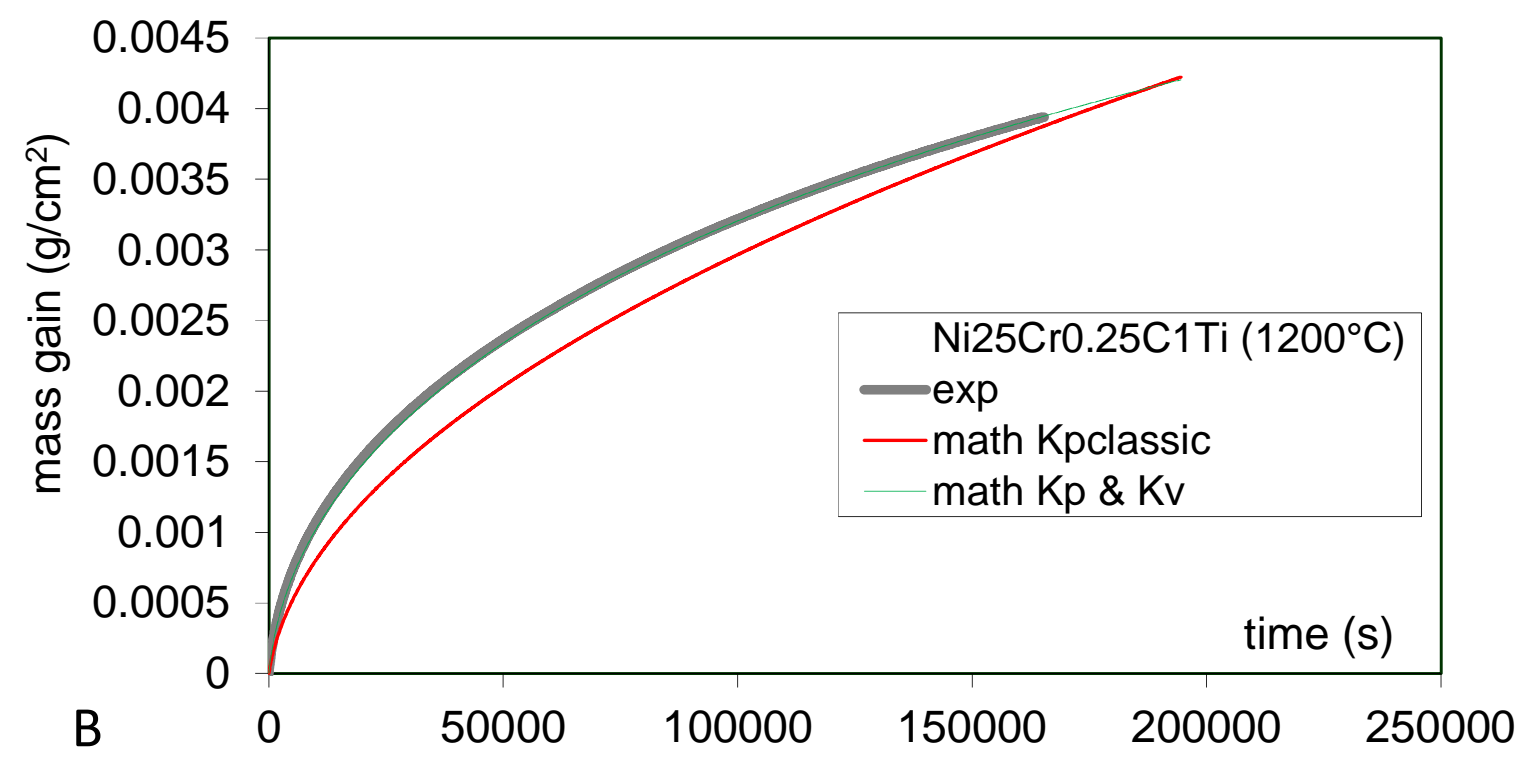

FIGURE 4. Exploitation of the mas gain files recorded for the NiTi1 alloy;

A: Treatment according to the $\{\mathrm{m} \times \mathrm{dm} / \mathrm{dt}=\mathrm{Kp}-\mathrm{K} \times \mathrm{m}\}$ method;

B: test of the $\mathrm{Kp}$ value classically determined and of the (Kp, Kv) couple of values issued from the treatment done above 


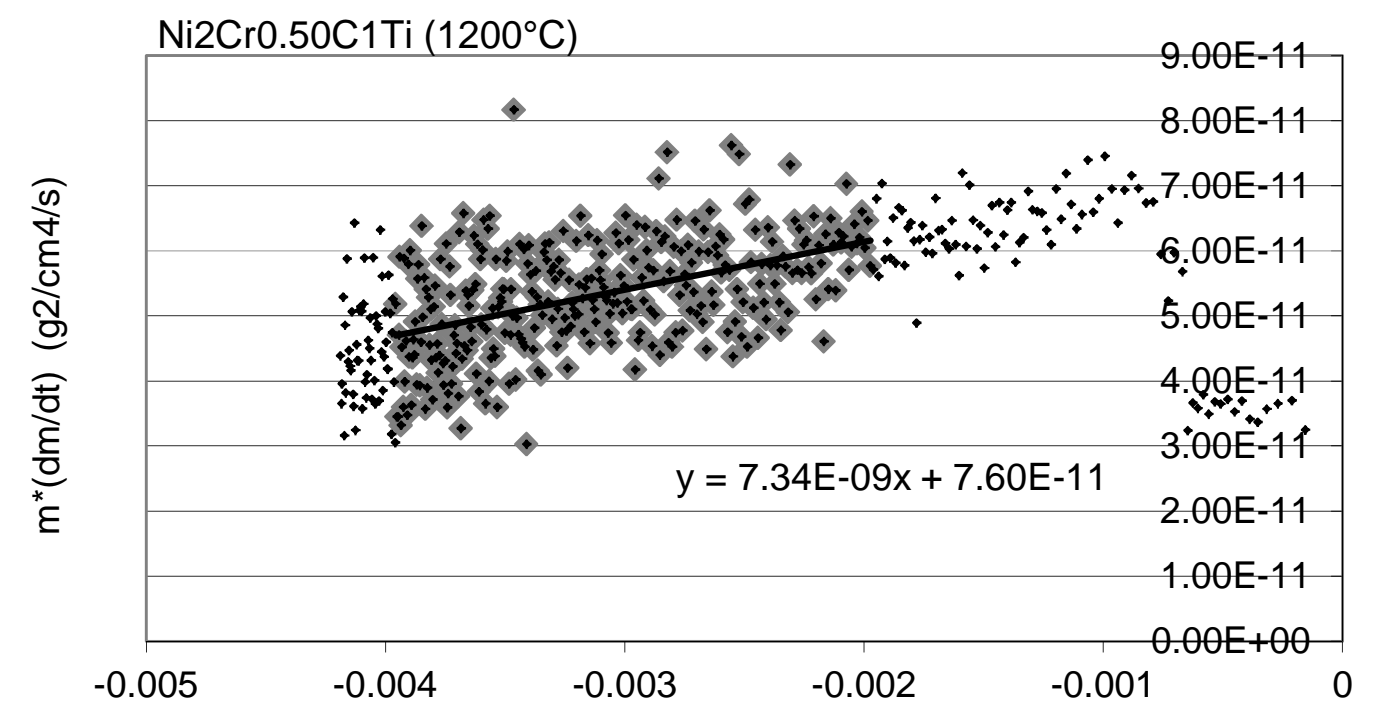

A - $\mathrm{m}$ (g/cm2)

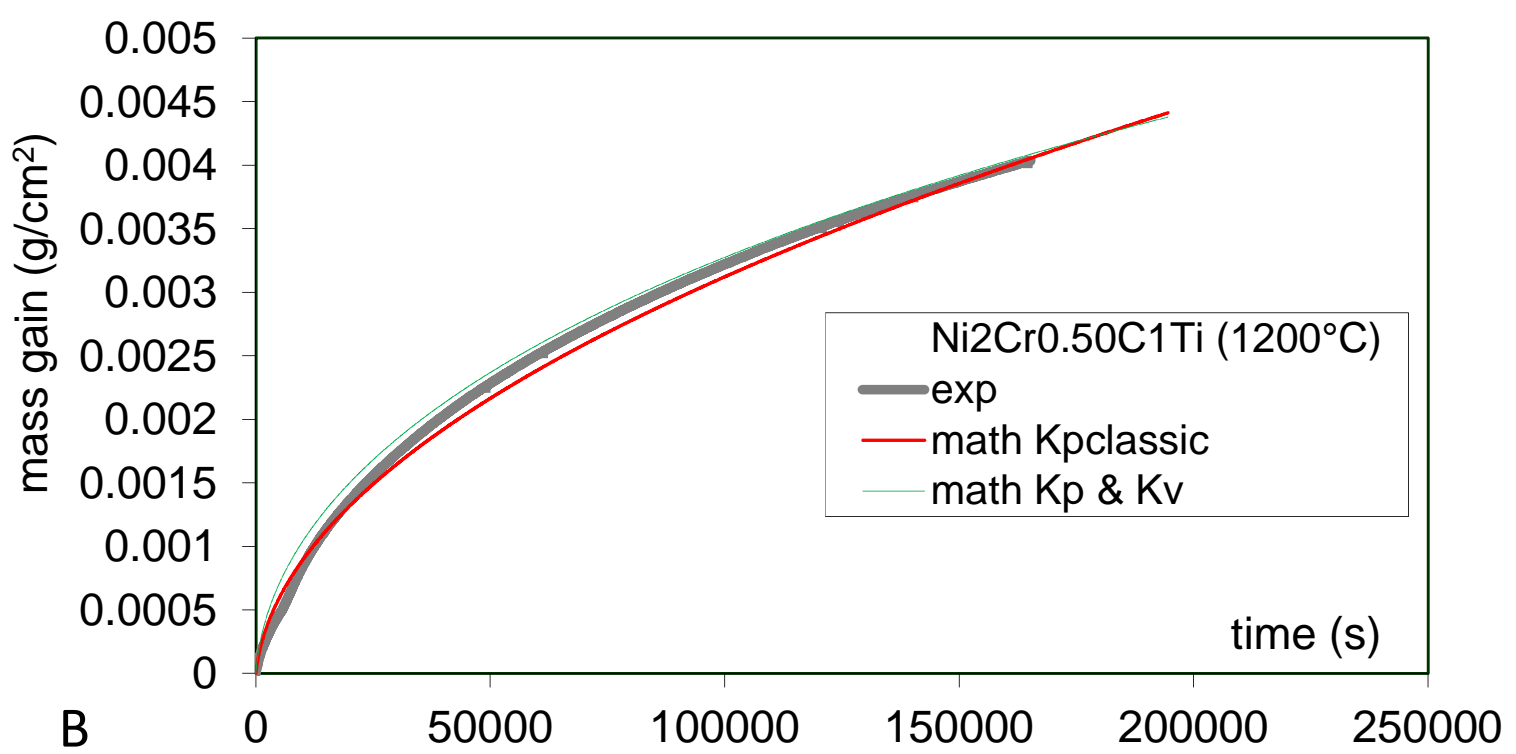

FIGURE 5. Exploitation of the mas gain files recorded for the NiTi2-1 alloy;

A: Treatment according to the $\{\mathrm{m} \times \mathrm{dm} / \mathrm{dt}=\mathrm{Kp}-\mathrm{K} \times \mathrm{m}\}$ method;

B: test of the $\mathrm{Kp}$ value classically determined and of the $(\mathrm{Kp}, \mathrm{Kv})$ couple of values issued from the treatment done above 


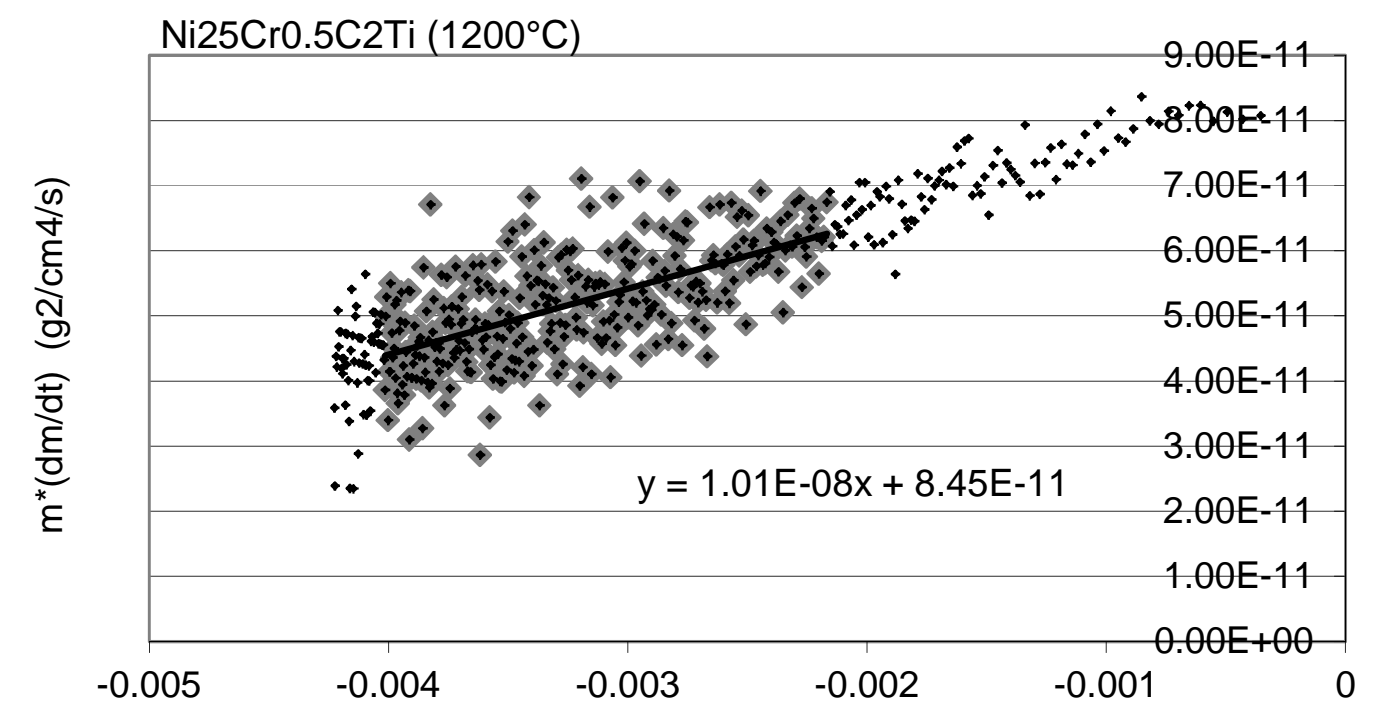

A

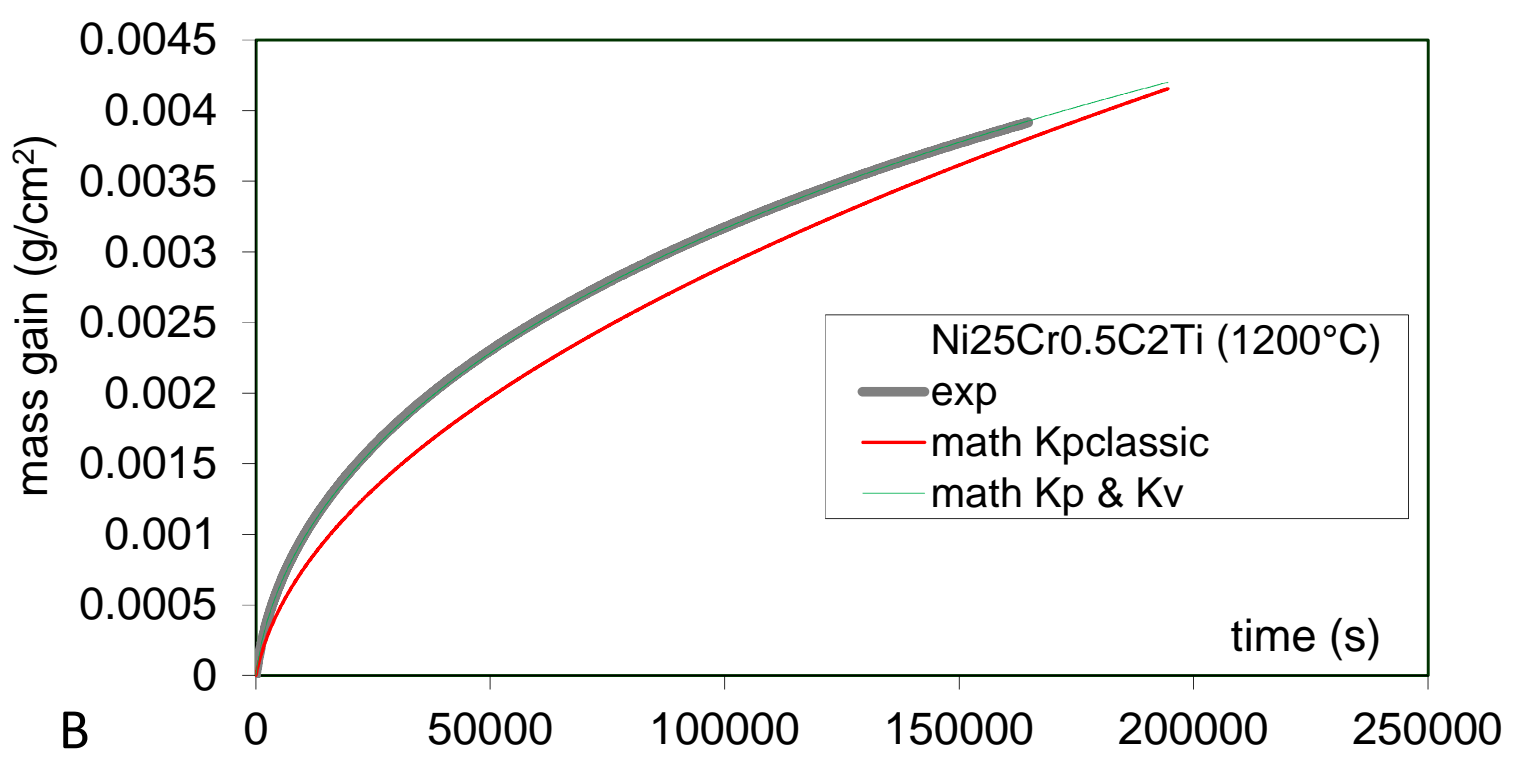

FIGURE 6. Exploitation of the mas gain files recorded for the NiTi2-2 alloy;

A: Treatment according to the $\{\mathrm{m} \times \mathrm{dm} / \mathrm{dt}=\mathrm{Kp}-\mathrm{K} \times \mathrm{m}\}$ method;

B: test of the Kp value classically determined and of the (Kp, Kv) couple of values issued from the treatment done above 


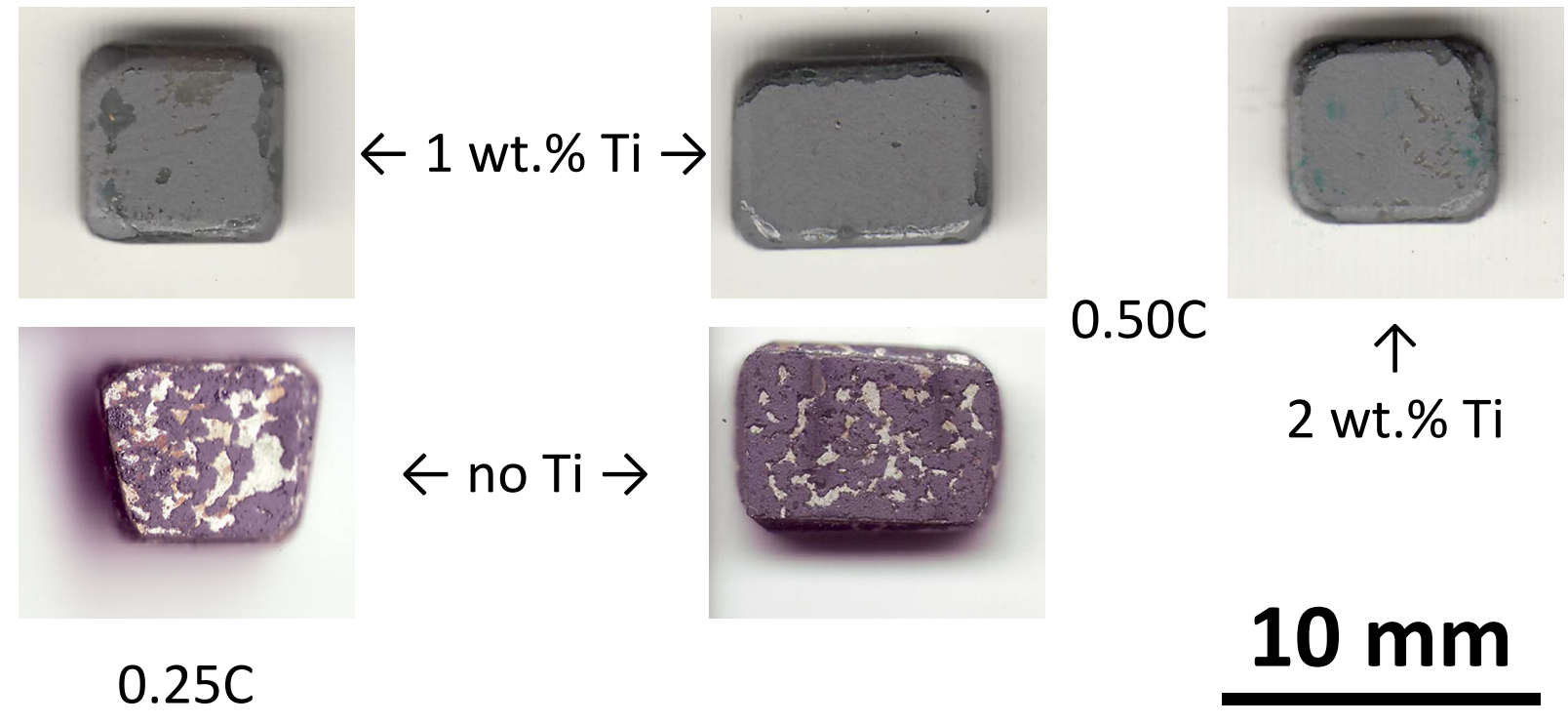

FIGURE 7. Aspects of the oxidized alloys after return to room temperature 


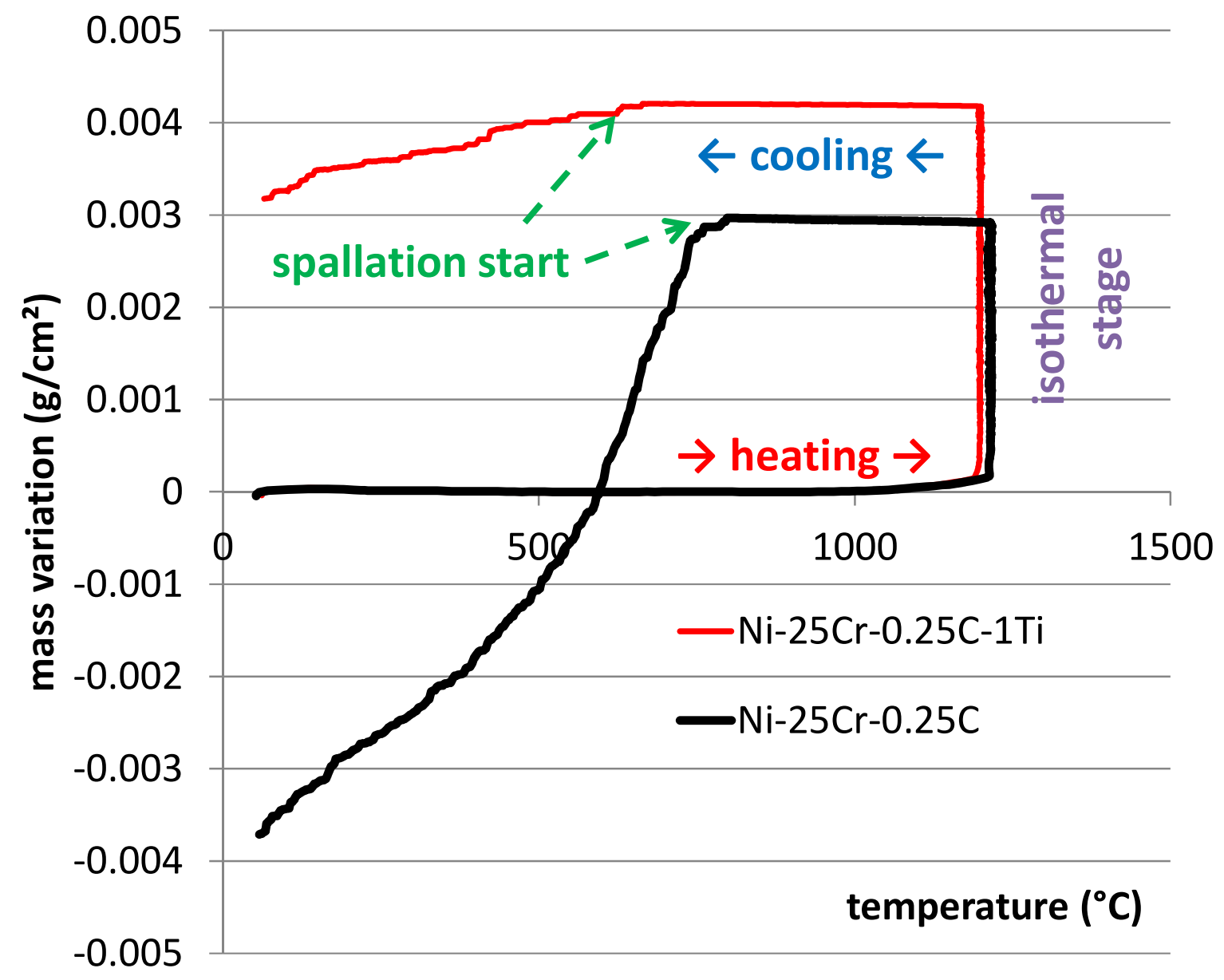

FIGURE 8. $\{\mathrm{m}$ versus temperature $\}$ plot of the mass gain files for evidencing the start of spallation during cooling (here: the two $0.25 \mathrm{C}$-containing alloys) 


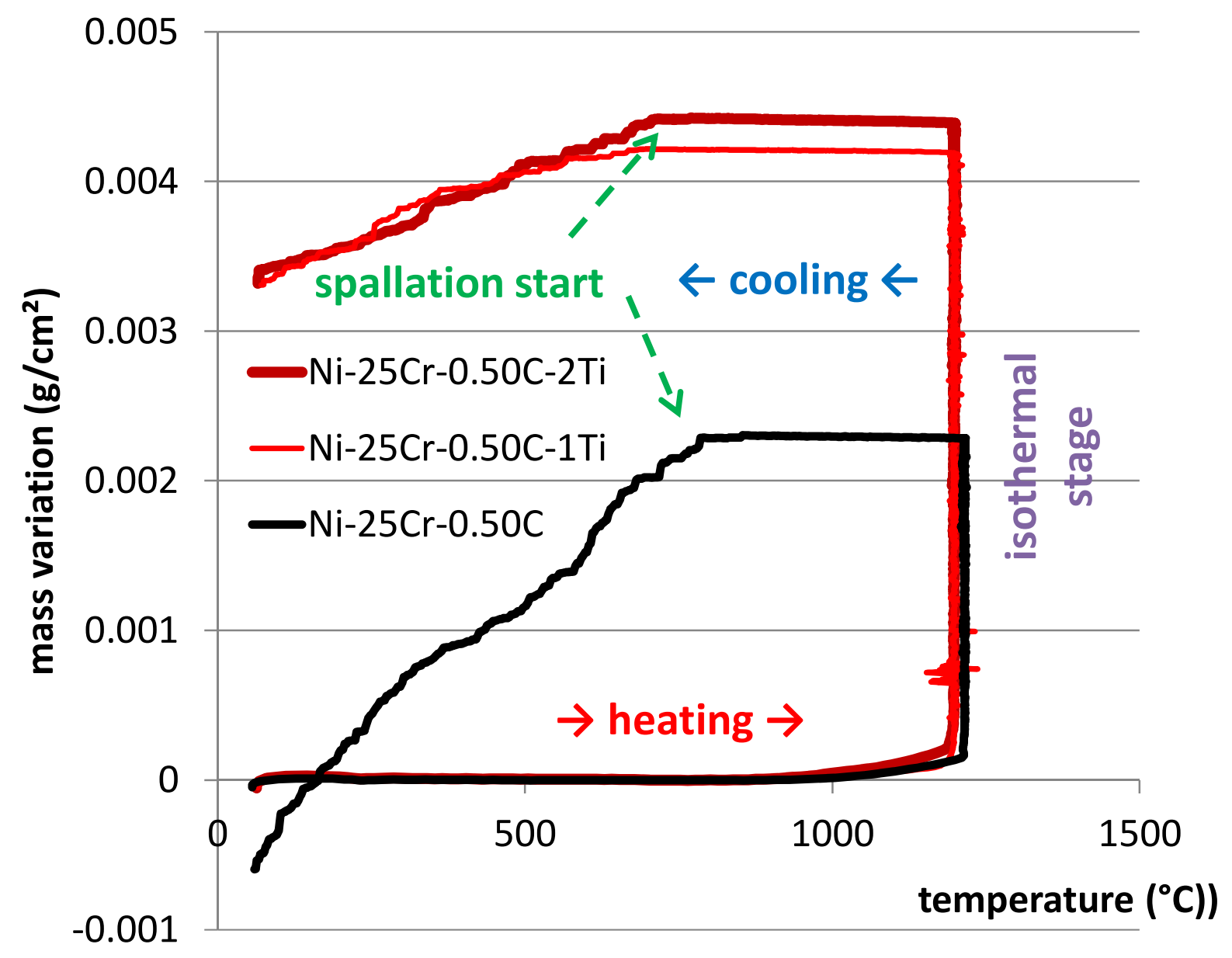

FIGURE 9. $\{\mathrm{m}$ versus temperature $\}$ plot of the mass gain files for evidencing the start of spallation during cooling (here: the two $0.25 \mathrm{C}$-containing alloys) 


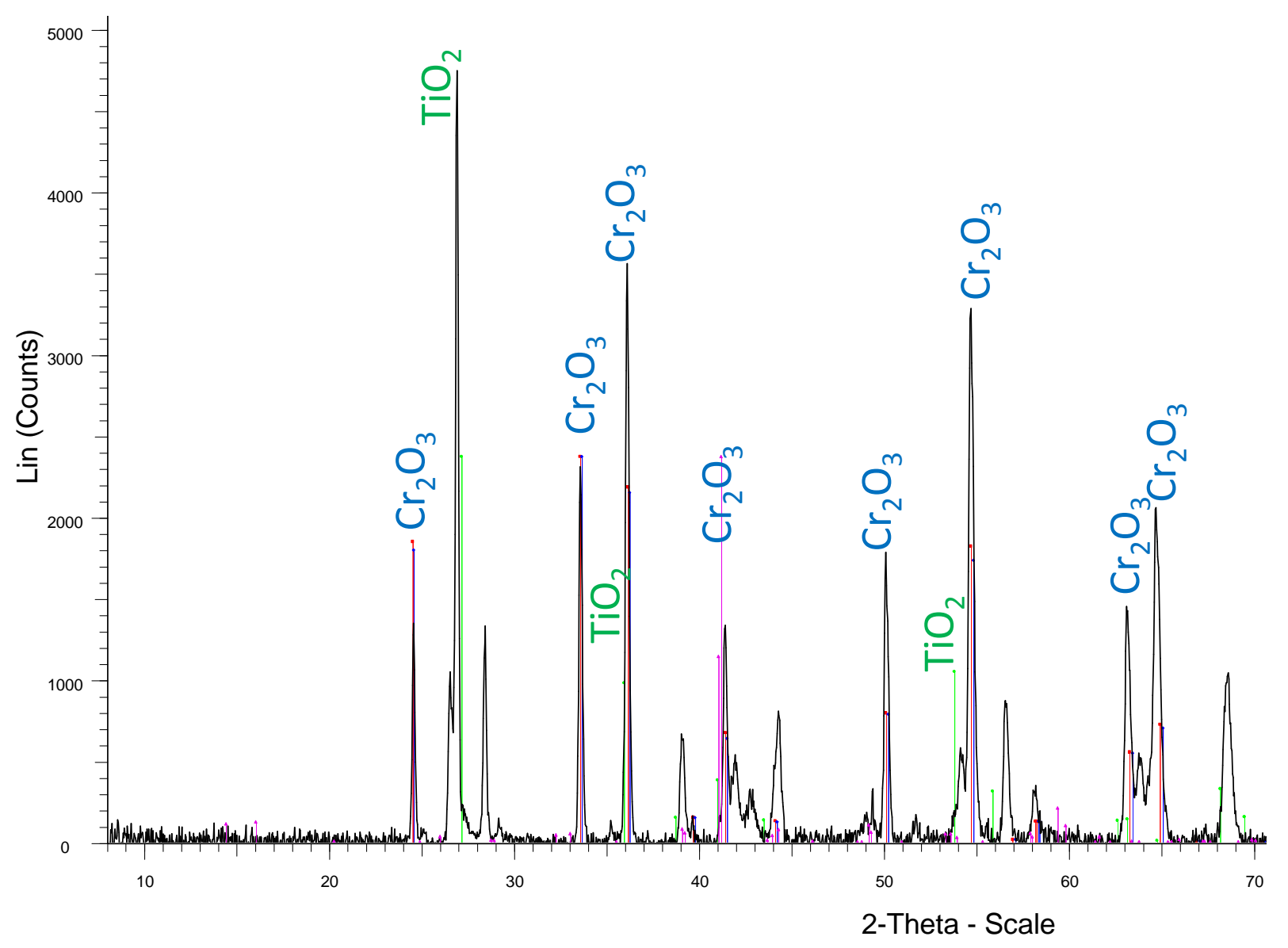

FIGURE 10. Diffractogram of the NiTil alloy after $46 \mathrm{~h}$ of oxidation at $1200^{\circ} \mathrm{C}$ (other peaks: matrix) 


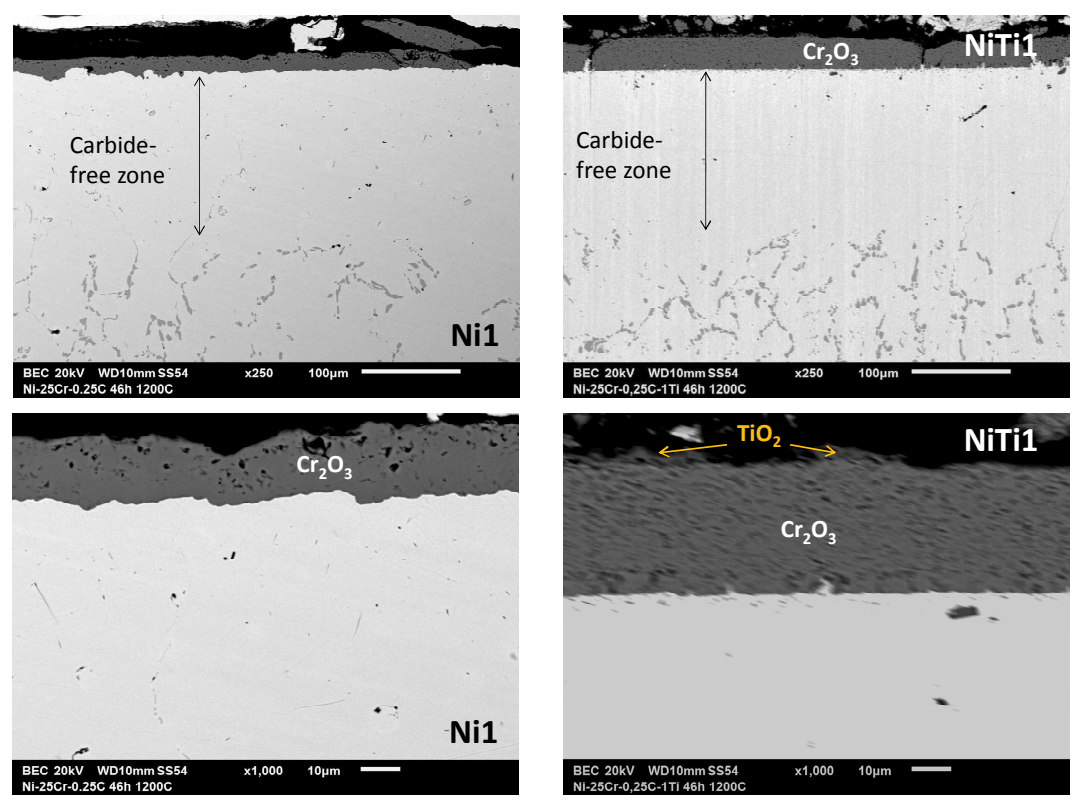

FIGURE 11. SEM/BSE micrograph of the oxidized surface of the Ni1 and NiTi1 alloys with the oxide identification
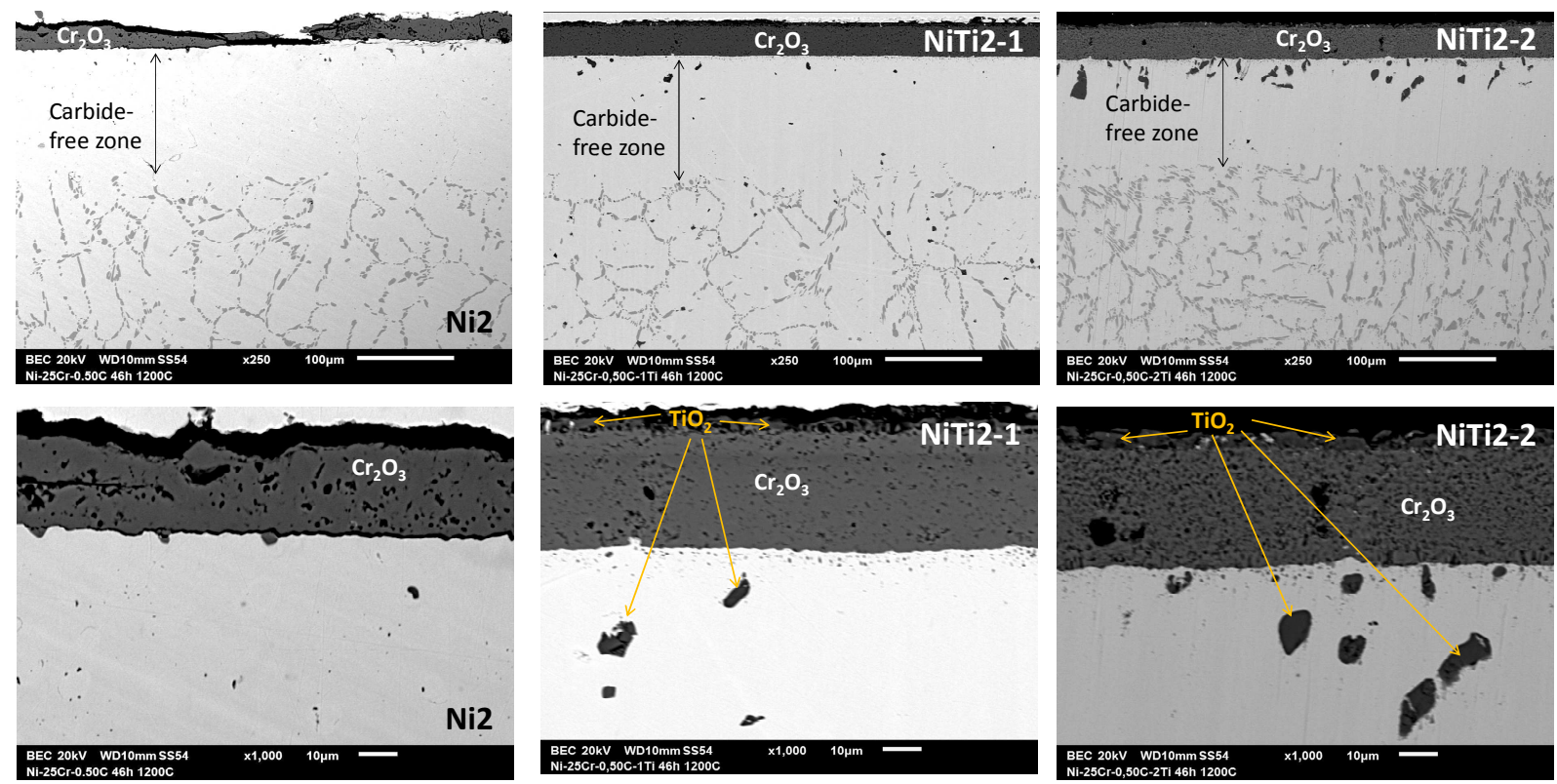

FIGURE 12. SEM/BSE micrograph of the oxidized surface of the Ni2, NiTi2-1 and NiTi2-2 alloys with the oxide identification 


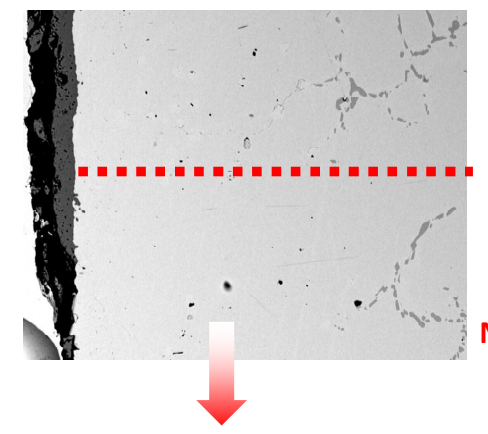

NiTi1
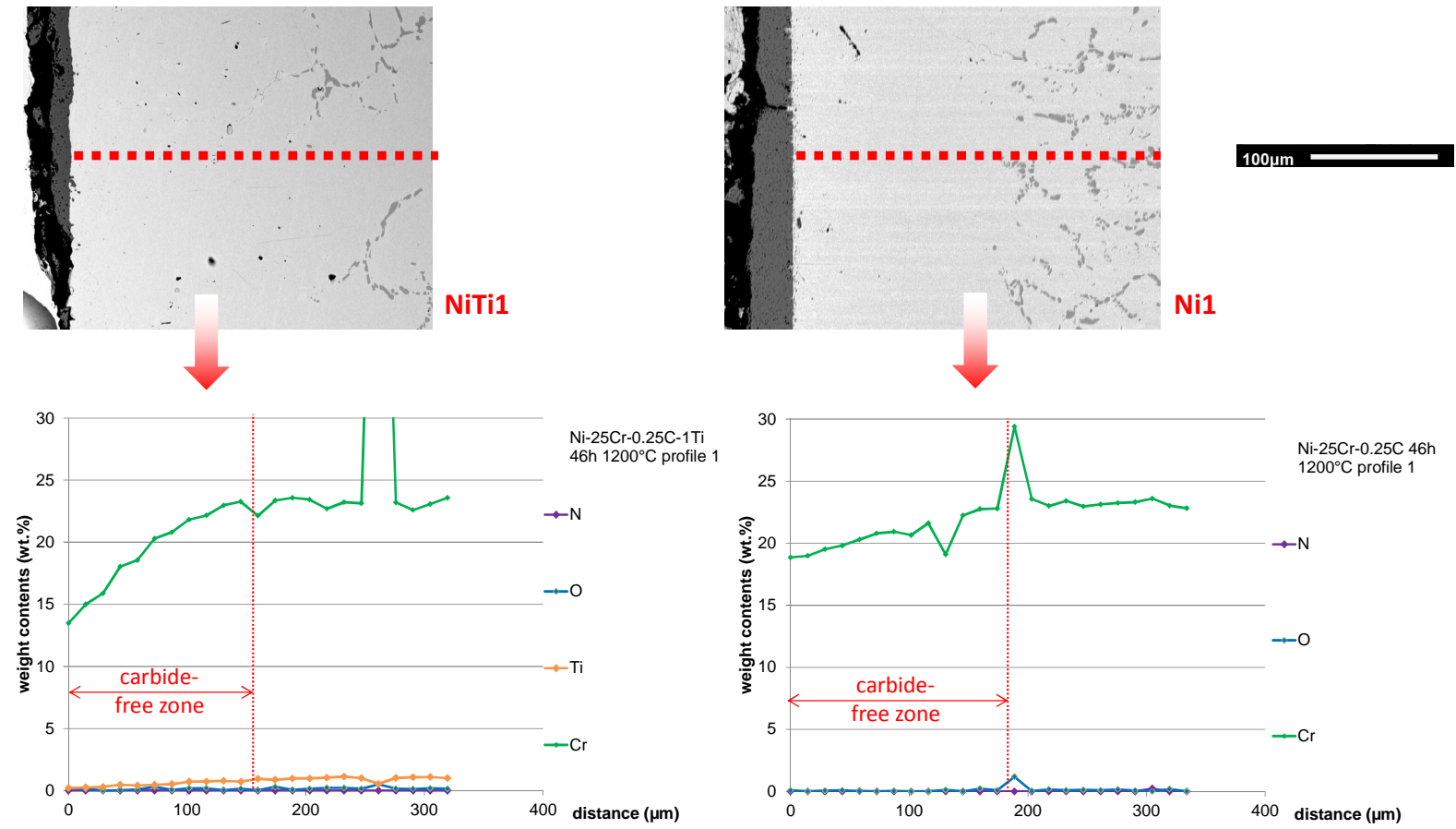

FIGURE 13. EDS concentration profiles in the subsurface (case of the two 0.25C-containing alloys: NiTi1 (left) and Nil (right) 

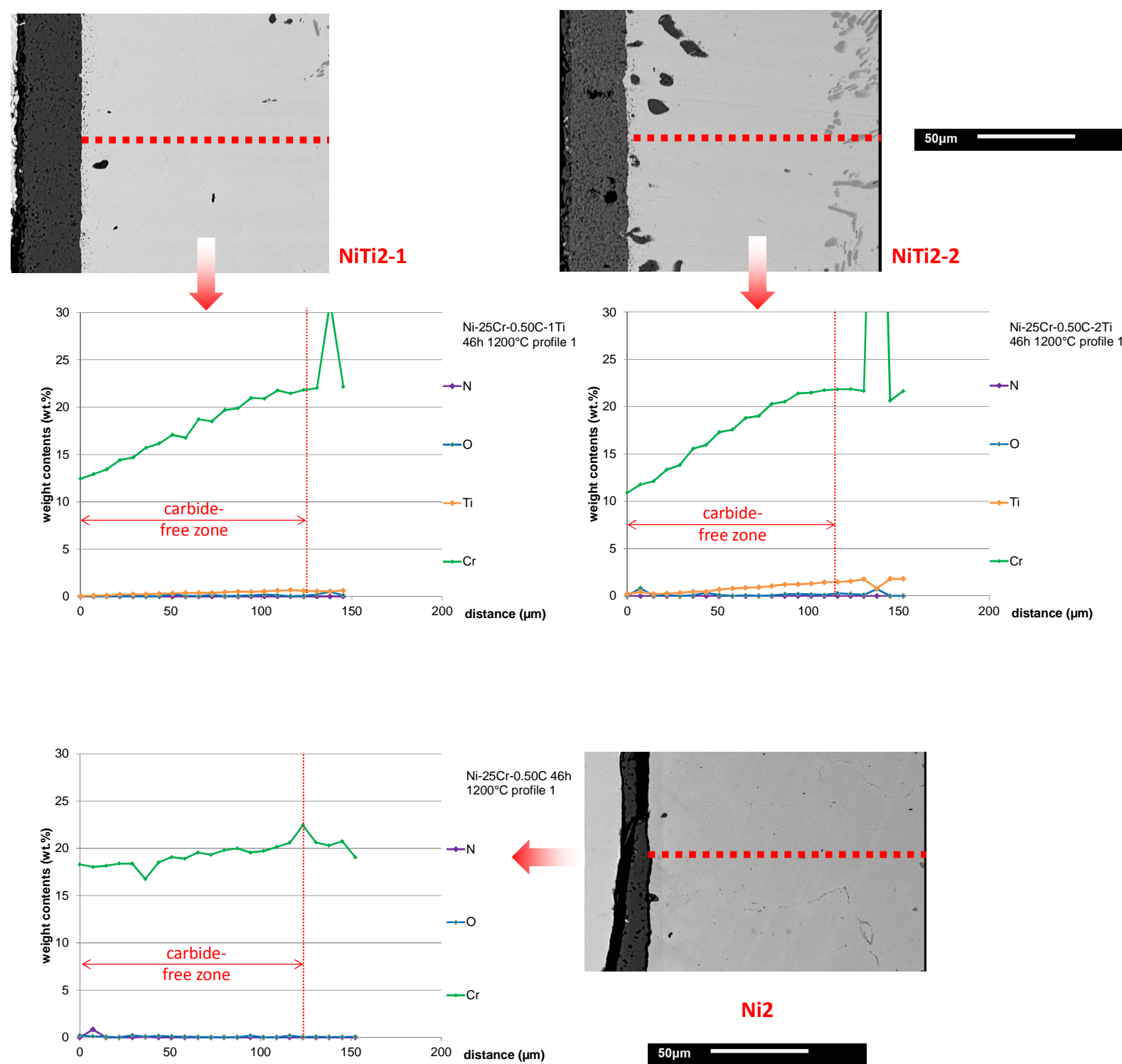

$\mathrm{Ni2}$

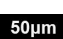

FIGURE 14. EDS concentration profiles in the subsurface;

case of the two 0.25C-containing alloys: NiTi2-1 (top left), NiTi2-2 (top right) and Ni2 (bottom) 